\title{
ACO Payment Models and the Path to Accountability
}

\author{
J. Michael McWilliams, $M D, P h D^{1,2}$ \\ 'Department of Health Care Policy, Harvard Medical School, Boston, MA, USA; ${ }^{2}$ Division of General Internal Medicine and Primary Care, Department of \\ Medicine, Brigham and Women's Hospital and Harvard Medical School, Boston, MA, USA.
}

J Gen Intern Med 29(10):1328-30

DOI: $10.1007 / \mathrm{s} 11606-014-2868-\mathrm{Z}$

(c) Society of General Internal Medicine 2014

$\mathrm{A}$ $\mathrm{s}$ the Centers for Medicare and Medicaid Services (CMS) deliberates on rules that will govern the next phase of Accountable Care Organization (ACO) initiatives in Medicare, ${ }^{1}$ its primary regulatory challenge is to strike a balance between promoting transformation of the delivery system and holding it accountable. How the pursuit of these goals unfolds could be determined largely by two key features of the ACO payment model - the spending target and the risk-sharing arrangement.

Currently, both the Medicare Shared Savings Program (SSP) and the Pioneer model set an ACO's spending target at the level of Medicare spending for beneficiaries served by the ACO before the contract period, projected forward by national growth in Medicare spending. Targets based on ACO spending history effectively impose pay-for-improvement incentives. The principal advantage of rewarding improvement is that it encourages providers to participate in the voluntary ACO programs. Regardless of an organization's level of efficiency or the complexity of its patient population, it can share in savings under the ACO model, as long as it bends its own curve. Because the least efficient provider organizations would likely not participate if held to national or local standards, the current model may be critical to engaging the most problematic parts of the delivery system in potentially corrective systems of payment.

Rewarding ACOs for improvement only, however, has two major drawbacks. First, if returns on efforts to control utilization diminish as an organization approaches maximum efficiency (i.e., after low-hanging fruit are picked), the current model could provide a competitive advantage to inefficient organizations. Consider two ACOs in the same market, one high-spending and one low-spending. If the

Supported by grants from the Laura and John Arnold Foundation, Beeson Career Development Award Program (National Institute on Aging K08 AG038354 and the American Federation for Aging Research), the Doris Duke Charitable Foundation (Clinical Scientist Development Award \#2010053), and the National Institute on Aging (P01 AG032952).

Published online April 29, 2014 high-spending ACO has more opportunities than the lowspending ACO to limit service use without harming patients at a cost less than the shared savings bonus, the current model would favor the high-spending organization. If the high-spending organization uses its profits as an ACO to expand or attract more patients, the net effect of ACO contracts in such a market would be to subsidize an overall increase in Medicare spending.

Second, pay-for-improvement incentives are weakened if the basis for improvement is updated to reflect changes in performance. Under the current Shared Savings Program payment model, for example, the spending level achieved by an ACO in one 3-year contract serves as the basis for its target in the next (Fig. 1). Rewards for lowering spending below a target are therefore limited to a single contract period, and bonuses are eventually negated by the fee-for-service profits foregone by maintaining spending at new (lower) targets. Accordingly, the current payment model may not allow ACOs to recoup the costs of redesigning systems of care and would not reward ACOs for maintaining efficient levels of spending after achieving them. In fact, because targets do not account for the costs of sustaining high efficiency, the current model would eventually penalize the most successful ACOs. Thus, although basing spending targets on historical spending may initially encourage ACO participation by permitting short-term gains for low-cost incremental improvements, continued application of this method to incumbent ACOs would diminish incentives for meaningful delivery system reform and may cause program departure.

For example, with an upfront investment of $\$ 3$ million and annual operating costs of $\$ 1$ million, suppose an ACO can achieve Medicare spending that is cumulatively $\$ 24$ million lower than expected over 10 years, including $\$ 1$ million lower per year from improvements during the first 3 years, an additional $\$ 2$ million lower per year from improvements in the next 3 years, and a maintenance phase of $\$ 3$ million less than expected over the following 4 years. Under the current model and assuming a shared savings rate of $50 \%$, the ACO would receive $\$ 4.5$ million in shared savings over the 10 years (all in the first 6 years) while spending $\$ 13$ million. Thus, the ACO would have no incentive to achieve these efficiencies or to continue as an $\mathrm{ACO}$ once it did. 


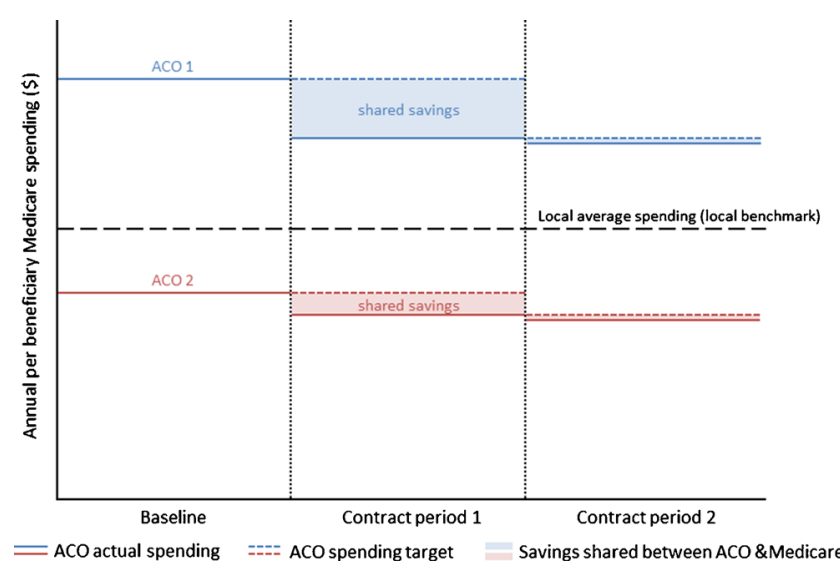

Figure 1. Two ACOs with different baseline spending levels. Two hypothetical ACOs are depicted, one with per-beneficiary Medicare spending above and one with per-beneficiary spending below local average spending for beneficiaries served by non-ACO providers. The ACO with high spending (ACO 1) achieves a lasting reduction in spending in the first contract period, but no further reduction in the second period. Under the current pay-forperformance model that bases spending targets on ACO-specific spending histories, ACO 1 receives a substantial shared savings

bonus in the first period but not in the second, because its spending target is reset at its new spending level. Under a payment model using local benchmarks as the basis for spending targets, ACO 1 would not be rewarded in either period, despite achieving substantial and lasting gains. The ACO with low spending (ACO

2) achieves a smaller spending reduction in the first contract period and no further reduction in the second period. Under the current model, it receives a small shared savings bonus in the first contract period and no bonus in the second. Relative to a target based on the local benchmark, however, it would receive a large bonus in both periods despite minimal improvement. Thus, the current model rewards ACO 1 for improvement (or at least mitigates its losses) in the short term, but provides weak long-term incentives for ACO 1 to achieve and sustain below-average spending like ACO 2. In contrast, a spending target based on a local benchmark would remove short-term incentives for ACO 1 to lower spending, but would provide strong long-term incentives for ACO 1 to achieve and sustain below-average spending. The advantages and disadvantages of the different methods for setting spending targets would depend further on the extent to which the ACOs' deviations from local average spending reflect differences in efficiency vs. differences in patient characteristics that are not described well by data available to Medicare.

Alternatively, risk-adjusted local benchmarks based on historical fee-for-service spending in a geographic area could be used to set ACO spending targets, as in Medicare Advantage. This method would strengthen incentives for improving and sustaining efficiency, but would reward ACOs with below-average spending simply for maintaining the status quo, and would discourage participation by inefficient providers who cannot attain a local average without incurring substantial losses in the short term (Fig. 1). Sufficient risk adjustment would be required to ensure that differences between ACO spending levels and the benchmark primarily reflect efficiency and not patient complexity. This may be challenging, as case mix may vary across ACOs and between $\mathrm{ACO}$ and non-ACO providers in ways that cannot be measured well with claims data. Under a payment model basing spending targets on local averages, insufficient risk adjustment would disadvantage ACOs serving sicker patients and could create strong incentives for all ACOs to attract healthier patients and refer costly patients elsewhere.

Use of local benchmarks raises other questions. In markets with high ACO penetration, how should a benchmark be set when average spending for beneficiaries served by non-ACO providers cannot be reliably assessed? A competitive bidding process could address this problem in markets with many competing ACOs, but how should benchmarks be set in markets dominated by one or two ACOs?

Like the thorny task of setting spending targets, specifying the risk arrangement in ACO payment models also presents a tradeoff between participation and the power of incentives to control costs. Under current rules, ACOs in the Shared Savings Program can opt for shared savings only (one-sided risk) in their first contract period, but are expected to assume risk for spending in excess of spending targets (two-sided risk) in subsequent contracts. In contrast, the Pioneer model requires ACOs to assume two-sided risk by the second year of their first contract. With over $90 \%$ of Shared Savings Program ACOs opting for one-sided risk, and nine of 32 ACOs leaving the Pioneer program after 1 year (seven switching to the SSP), ${ }^{2}$ the availability of one-sided arrangements has ostensibly encouraged participation. Under one-sided risk, however, incentives for ACOs to lower spending are much weaker, and random fluctuations in spending contribute to bonuses but not penalties for ACOs, constituting an expected loss for Medicare when net savings across all ACOs are minimal.

In structuring incentives for ACOs, Medicare thus faces familiar tradeoffs previously encountered in reforms of its payment systems for hospitals and managed care plans. ${ }^{3,4}$ While the ACO programs mark a significant departure from fee-for-service payment, the drive for greater accountability must be paced by the slow work of reorganizing the practice of medicine. To strike the right balance, CMS will likely need to embrace flexible payment models to successfully guide a diversity of provider organizations with different starting points down a path of delivery system transformation and accountability. With the right mix of inducements and constraints, an adaptive model offering ACOs options along the way could ensure progress on both fronts.

For example, all ACOs could be required to participate in the current pay-for-improvement model for initial contract periods, and those achieving savings (as determined by comparisons with valid control groups) could then be allowed to opt for spending targets based on local benchmarks (or a blend of local and ACO-specific spending histories if risk adjustment is insufficient). In sufficiently competitive markets, benchmarks could be determined by a bidding process. To encourage improvement at any level of efficiency, CMS could additionally permit ACOs to continue one-sided risk arrangements as long as they achieve savings in the previous period, but require them to switch permanently to two-sided risk-sharing when improvement has slowed. Finally, to keep organizations on the ACO path, CMS could make the traditional Medicare program less 
attractive for providers; for example, by lowering Part B premiums for beneficiaries choosing Medigap plans with ACOs as preferred providers, or by allowing ACOs to waive copays for office visits or prescription drugs. Thus, provider groups leaving the ACO programs would risk losing patients to participating groups. From Medicare's perspective, such an approach could encourage participation in ACO programs while limiting undeserved rewards and strengthening incentives to achieve and maintain greater efficiency. For participating organizations, a model that presents options as ACOs evolve, adapts to levels of efficiency, and limits unwarranted penalties should preserve self-determination and fairness.

With over 360 participating organizations and growing, the Medicare ACO initiatives have clearly tapped into a groundswell of interest in making the practice of medicine more cost-effective. To build on this initial success will require nimble payment policy that engages the delivery system, gives it time and incentives to restructure, but holds it accountable when it can deliver.
Corresponding Author: J. Michael McWilliams, MD, PhD; Department of Health Care Policy, Harvard Medical School, 180 Longwood Ave, Boston, MA 02115, USA (e-mail: mcwilliams@hcp.med.harvard.edu).

\section{REFERENCES}

1. Center for Medicare and Medicaid Innovation. Request for Information: Evolution of ACO Initiatives at CMS. 2014. (Accessed March 14, 2014, at http://innovation.cms.gov/Files/x/Pioneer-RFI.pdf.)

2. Centers for Medicare and Medicaid Services. Pioneer Accountable Care Organizations succeed in improving care, lowering costs., 2013. (Accessed March 14, 2014, at http://www.cms.gov/Newsroom/ MediaReleaseDatabase/Press-Releases/2013-Press-Releases-Items / 2013-07-16.html.)

3. Medicare Payment Advisory Commission. Report to the Congress: Medicare Payment Policy. 1999; p72. (Accessed March 14, 2014, at http:// www.medpac.gov/documents/Mar99\%20Entire\%20report.pdf.)

4. Centers for Medicare and Medicaid Services. Medicare Hospital Valuebased Purchasing Program. (Accessed March 14, 2014, at http:// www.cms.gov/Medicare/Quality-Initiatives-Patient-Assessment-Instruments/hospital-value-based-purchasing/index.html?redirect=/hospitalvalue-based-purchasing.) 